in combination with methotrexate. Open studies with a few number of patients suggested that infliximab as monotherapy is also effective in active spondyloarthropathies.

Objectives To evaluate the efficacy of infliximab as monotherapy in patients with refractory and active spondyloarthropathy.

Methods Thirty-eight week, open, multicentric and prospective trial, in 42 patients with spondyloarthropathy, according the ESSG and/or Amor criteria. All patients have disease duration of more than one year and persistent disease activity despite use of different drugs (NSAIDs, sulfasalazine, methotrexate or pamidronate). Infliximab is administered at a dose of $5 \mathrm{mg} / \mathrm{kg}$, at $0,2,6$, 14, 22 and 30 weeks. Clinical assessment was performed at these weeks at a week 38 . Different clinical disease activity measures are performed, including BASDAI and patient global assessment of disease status. Disability is measured by BASFI and HAQ-Sp. ESR and CRP is used as laboratory parameters of inflammation. Results Preliminary results at week 0,2 and 6 in 10 patients $(3 F /$ 7M): 8 AS patients and 2 undifferentiated spondyloarthropathy; mean age: $36 \pm 7 \mathrm{yr}$, mean disease duration: $14 \pm 6 \mathrm{yr}$ are presented in this Table 1 .

In all patients a significant improvement in clinical, functional and laboratory parameters were observed. This improvement was seen at week 2 (after the first dose) and is maintained at week 6.

\begin{tabular}{llllll}
\multicolumn{6}{l}{ Abstract OP0059 Table 1} \\
\hline $\begin{array}{l}\text { BASDAI } \\
(\mathbf{m} \pm \mathrm{sd})\end{array}$ & $\begin{array}{l}\text { BASFI } \\
(\mathrm{m} \pm \mathrm{sd})\end{array}$ & $\begin{array}{l}\text { GLOB ASSESS } \\
(\mathrm{m} \pm \mathrm{sd})\end{array}$ & $\begin{array}{l}\text { ESR }(\mathrm{mm}) \\
(\mathrm{m} \pm \mathrm{sd})\end{array}$ & $\begin{array}{l}\text { CRP }(\mathrm{mg} / \mathrm{dl}) \\
(\mathrm{m} \pm \mathrm{sd})\end{array}$ \\
\hline Week 0 & $7.47 \pm 1.05$ & $6.80 \pm 1.31$ & $8.06 \pm 1.09$ & $51 \pm 32$ & $35.8 \pm 29.3$ \\
Week 2 & $3.52 \pm 2.44^{*}$ & Not evaluate & $3.97 \pm 2.06^{*}$ & $18 \pm 17^{*}$ & $4.5 \pm 4.1^{*}$ \\
Week 6 & $3.12 \pm 1.43$ & $3.16 \pm 1.85$ & $3.38 \pm 1.79$ & $11 \pm 18$ & $3.5 \pm 3.1$ \\
\hline${ }^{*} \mathrm{p}<0.01$. & & & & \\
\end{tabular}

Conclusion Preliminary results of this open study show that infliximab provides a quick and significant clinical improvement in refractory spondyloarthropathies.

\section{OP0063 THREE MONTHS RESULTS OF A DOUBLE-BLIND PLACEBO CONTROLLED, PHASE-III CLINICAL TRIAL OF INFLIXIMAB IN ACTIVE ANKYLOSING SPONDYLITIS}

\footnotetext{
${ }^{1} \mathrm{~J}$ Brandt, ${ }^{2} \mathrm{R}$ Alten, ${ }^{3} \mathrm{G}$ Burmester, ${ }^{4} \mathrm{E}$ Gromnica-lhle, ${ }^{5} \mathrm{H}$ Kellner, ${ }^{6} \mathrm{M}$ Schneider, ${ }^{7} \mathrm{H}$ Sörensen, ${ }^{8} \mathrm{H}$ Zeidler, ${ }^{9} \mathrm{~W}$ Thriene, ${ }^{10,11} \mathrm{~J}$ Sieper, ${ }^{12} \mathrm{~J}$ Braun. ${ }^{1}$ Nephrology, Benjamin Franklin Hospital, Free University Berlin; ${ }^{2}$ Schlosspark-Clinic, Berlin; ${ }^{3}$ Rheumatology, Humboldt University, Berlin; ${ }^{4}$ Rheumatology-Hospital Berlin-Buch; ${ }^{5}$ Rheumatology, Ludwig-Maximilians-University, Munich; ${ }^{6}$ Rheumatology, Heinrich Heine University, Duesseldorf; ${ }^{7}$ Immanuel-Hospital, Berlin; ${ }^{8}$ Rheumatology, University of Hannover; ${ }^{9}$ Essex Pharma, Munich, Germany; ${ }^{10}$ Gastroenterology/Rheumatology, Benjamin Franklin Hospital, Free University Berlin; ${ }^{11}$ German Rheumatology Research Center, Berlin; ${ }^{12}$ Rheumazentrum Ruhrgebiet, Herne
}

\subsection{6/annrheumdis-2001.352}

Background Recently, patients with severe ankylosing spondylitis (AS) significantly improved upon treatment with the anti-tumour necrosis factor a (TNFa) antibody infliximab (RemicadeR) in an open pilot study (A\&R June 2000). Therefore, a placebo-controlled trial was designed to prove that the administration of infliximab has a beneficial effect on the short and long term course of severe AS.

Objectives

Methods Seventy patients (47 men, 23 women) with a mean age of 39.2 years and proven AS (1984 New York criteria) in an active stage of disease were included in the study. Active disease was defined as a Bath AS Disease Activity Index (BASDAI) $>4$ and pain $>4$ on a numeric rang scale (NRS). The patients were randomised into two groups of 35 patients each which received either infliximab in a dosage of $5 \mathrm{mg} / \mathrm{kg}$ i.v. or placebo. Infusions were given at week 0,2 and 6 and then every 6 weeks until week 48. The BASDAI, BASFI (Functional Index), BASMI (Metrology Index), pain on a NRS, quality of life by the SF36 and CRP were measured. Patients with $>50 \%$ improvement of BASDAI was defined as a responder. The study started on August 15th 2000; the last patient was included on 19th October 2000. Results The last patient has finished the placebo-controlled part of the study on January 25th 2001. Sixty-six patients have completed the three-months placebo-controlled period. One patient developed tuberculosis. The three-months-follow up data which are just being analysed are presented at the EULAR-Meeting in June 2001.

Conclusion The subjective therapeutic efficacy in some of the patients was impressive but the results of the ongoing analysis have to be awaited.

\section{SAT0001 ROLE OF DETERMINATION OF SUCCINATE DEHYDROGENASE, MYELOPEROXIDASE, NA $\pm K \pm$ ATPH-ASE, 5?-NUCLEOTIDASE IN CELLS OF PERIPHERAL BLOOD OF ANKYLOSING SPONDYLARTHRITIS PATIENTS}

AB Zborovsky, BV Zavodovsky, TA Pankratova, AV Rvachev, OV Bykova, TV Serdukova. Laboratory for Arthritis and Arthrosis, Research Institute for Clinical and Experimental Rheumatology, Volgograd, Russia

\subsection{6/annrheumdis-2001.353}

\section{Background}

Objectives To assess the value of determination Myeloperoxidase (MP), $\mathrm{Na} \pm \mathrm{K} \pm \mathrm{AOPh}$-ase (ATPh-ase), 5'-Nucleotidase (5?NT), Succinate dehydrogenase (SDG) in cells of peripheral blood of ankylosing spondylarthritis (AS) patients.

Methods We observed 30 AS patients and 30 healthy donors (HD) as control group. The activities of enzymes were determined by hystochemical methods.

Results We observed increasing of ATPh-ase in neutrophils and lymphocytes, MP in monocytes, 5?-NT in lymphocytes, monocytes and neutrophils, decreasing of MP in neutrophils $(\mathrm{p}<$ $0,05)$. We observed the greatest increasing of ATP-ase in neutrophils in 1st degree of AS activity, 5?NT in all cells and MP in monocytes - in fast progressing AS. Level of SDG in lymphocytes in AS did not differ from HD. There were correlation between level MP in neutrophils and expressiveness of an anaemia $(r=-0,41, p=0,029)$. Reliable dynamics of enzymes activities were noted during the course of treatment. We revealed normalisation of MP in monocytes and neutrophils when the patients received indomethacin. There were decreasing of 5 ?NT level at the treatment by NSAIDs and steroid hormones. There was correlation of clinical improvement with activity of 5 ?NT in blood cells.

Conclusion The determination of MP, ATPh-ase, 5?-NT, but not SDG activities in blood cells can be used for improvement of quality of AS diagnostics and for control of treatment quality. 


\section{SAT0002 COMPARISON OF TWO EXERCISE REGIMENS IN PATIENTS WITH ANKYLOSING SPONDYLITIS}

KK Trnavsky, Y Sulcova, J Knebortova. Rheumatology, Postgraduate Medical School, Arthocentrum, Praha, Czech Republic

10.1136/annrheumdis-2001.354

Background Exercise alone can produce adequate relief of symptoms in ankylosing spondylitisi (AS) and manipulative therapy has also been shown to improve range of movement in short ? time.

Objectives To compare the effect of a dynamic individual rehabilition regimen with a simple conservative exercise regimen (exercies in goups).

Methods Forty patients with established AS, mean age 51 years and mean disease duration 10 years were randomly assigned to group of 20 patients each. The treatment programme consisted of two thre ? months periods.: A. Intensive individual programme (assisted by an experienced physiotherapist) included thermotherapy. Soft techniques, relaxation of shortened muscles, breathing exercises. B. Current exercise programme in groups. Metrologic assessment and questionnaires were used to evaluate the activity of the process (BASDAI) and the functional handicap of the patient (BASFI). In the first group of patients both the programme A and B were applied. The second group underwent only programme B. After 3 months the therapeutic programmes in the two groups were exchanged.

Results The combined exercise regimen involving individual therapeutic care resulted in improvement of parameters assessing spinal column mobility ? Schober "s distance, tips to the floor distance, incluination and retro ? and anteflexion of cervical column. The indicators of function and disease activity evaluated according to BASDAI and BASFI questionnaires showed also improvement but the differences did no reach statistical significance over the three-months period of follow-up.

Conclusion Intensive individual exercise programme including soft techniques and relaxation of shortened muscles is more effective in AS than a conservative programme based on exercise in groups.

\section{SAT0003 INTESTINAL COLONISATION WITH SULPHATE-REDUCING BACTERIA: A CO-FACTOR IN THE AETIOPATHOGENESIS OF ANKYLOSING SPONDYLITIS?}

${ }^{1} \mathrm{SM}$ Stebbings, ${ }^{1} \mathrm{~J}$ Highton, ${ }^{2} \mathrm{G}$ Tannock. ${ }^{1}$ Rheumatology; ${ }^{2}$ Microbiology, University of Otago School of Medicine, Dunedin, New Zealand

\subsection{6/annrheumdis-2001.355}

Background Sulphate-reducing bacteria (SRB) have only recently been identified as a constituent of the normal colonic microflora humans. Such colonisation however is far from universal. Small studies in patients with ulcerative colitis (UC) have found SRB to be present in up to $92 \%$ of patients and a pathogenic role has been speculated. Approximately $65 \%$ of patients with ankylosing spondylitis (AS) have colonic inflammation, and this is now recognised as an independent risk factor for the disease. Furthermore, studies in germfree HLA-B27 transgenic rats have shown that the normal intestinal microflora is essential to the development of spondyloarthritis in these animals.

Objectives We aimed to discover whether intestinal colonisation with SRB was more common in AS patients than controls, and thus whether SRB may play a role in the aetiology of AS.
Methods Fifteen patients fulfilling the Modified New York criteria for AS and 15 age and gender matched controls were recruited. Each subject provided 3 faecal specimens at monthly intervals. Bacterial DNA extracts were obtained from 3 faecal samples from 14 patients and 14 controls, and one each from the remaining patient and control. PCR was performed using primers targeting a conserved region of subunit $\mathrm{A}$ of the adenosine-5?-phosphosulphate (APS) reductase gene a gene conserved across all SRB species.

Results (See Table 1)

Chi-square with Yates? correction demonstrated a highly significant association between AS and colonisation with SRB ( $\mathrm{p}=$ 0.003).

\begin{tabular}{llll}
\multicolumn{4}{l}{ Abstract SAT0003 } \\
\hline & Pable 1 & & \\
\hline Ankylosing spondylitis & $24(56 \%)$ & $19(44 \%)$ & 43 \\
Controls & $7(16 \%)$ & $36(84 \%)$ & 43 \\
Total number of samples & & & 86 \\
\hline Identification of sulphate-reducing bacteria in faecal samples using PCR.
\end{tabular}

Conclusion We have discovered a much higher prevalence of faecal carriage of SRB in patients with AS compared with healthy controls. This raises the possibility that these organisms may play a role in the aetiopathogenesis of AS. An alternative possibility is that SRB reflect the presence of colonic inflammation in these individuals.

\section{REFERENCES}

1 Gibson GR, Cummings JH, Macfarlane GT. Growth and activities of sulphatereducing bacteria in gut contents of healthy subjects and patients with ulcerative colitis. FEMS Microbiol Ecol. 1991;86:103-12

2 Veys EM, Mielants $H$, De Vos M, Cuvelier C. Spondylarthropathies: from gut to target organs. Baillieres Clin Rheumatol. 1996;10(1):123-46

3 Taurog JD, Richardson JA, Croft JT, et al. The germfree state prevents development of gut and joint inflammatory disease in HLA-B27 transgenic rats. J Exp Med. 1994;180(6):2359-64

\section{SATO004 IS THE ASSOCIATION SJÖGREN'SYNDROME- SPONDYLARTHROPATHY FORTUITOUS?}

C Scotto di Fazano, E Quennesson, S Quennesson, RM Grilo, D Couaral, P Vergne, C Bonnet, P Bertin, R Treves. Rheumatology, Universitary Hospital Dupuytren, Limoges, France

\subsection{6/annrheumdis-2001.356}

Background Secondary Sjögren's syndrome is known to occur with rheumatoid arthritis, systemic lupus erythematosus, but apart from a few cases, has not been reported with spondylarthropathy (SpA).

Objectives To determine the prevalence of Sjögren's syndrome in spondylarthropathy patients.

Methods Patients with SpA ( $\mathrm{n}=62)$ with inflammatory back pain and/or peripheral arthritis were diagnosed as Ankylosing Spondylitis (AS), undifferentiated SpA (uSpA), psoriatic Arthritis (PA), and arthritis associated with inflammatory bowel diseases (IBD). The investigation of sicca symptoms in the group SPD and healthy controls $(n=102)$ was based on a valited questionnaire. Patients with $\mathrm{SpA}$ with sicca symptomes and/or positive antinuclear antibodies (ANA) were investigated for Sjögren's syndrome by minor salivary gland biopsy. 